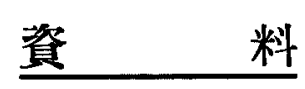

\title{
The Globose Character of the Japanese Morning Glory in CONNECTION With THE IMPROVEMENT OF ITS Flower SizE
}

\author{
Yoshitaka IMAI \\ Botanical Institute, Agricultural College, Tokyo Imperial University
}

The development of the Japanese morning glory, Pharbitis Nil, for ornamental purposes has proceeded in two directions, to large flowers and monstrous doubles. Large flowers have been appreciated from olden times, as far back as about i 20 years ago, although in those days they were not so very evident, their cultivation in earnest dating back only to about 30 or 40 years ago. At present the largest flower attains to 7 Sun (or about $2 \mathrm{I} \mathrm{cm}$, the Japanese Sun being about $3.03 \mathrm{~cm}$ ) or more in diameter. The large flowers, the causes of which are genetic, are manifested mainly by a gene called retracted, which is a simple recessive to normal. Although gene retracted causes the lobes of the leaves to shorten and retract, it at the same time enlarges the flower, the number of petals frequently exceeding five. Owing to deformity of the pistilate organs to a certain extent, fertility is below normal. The seedlings can be definitely identified by the shortened, roundish lobes of the cotyledons-an advantage in that it saves labor in selecting the retracted seedlings. Although the origin of gene retracted is not clear, it is certain that the time when it first occurred by sporadic mutation from normal is not very far back. Mr. T. Ozaki of Koganei, near Tokyo, informs me that he was told by the late Mr. Z. Hanai of Osaka, that the lastnamed, in 1903 , discovered some retracted seedlings that had occurred spontaneously in a naturally raised hybrid progeny, this being said to be the origination of our retracted. At that time the record of the largest flower (not-retracted) was a little over 5 Sun, while the mutants bloomed into 6 Sun-an innovation in the flower size of this plant. Mr. Ozaki's information will serve as a reference in connection with the origin of the retracted character. I hope some day, to collect proofs substantiating this view.

The improvement made with respect to the retracted flowers gradually led to increase in flower size, due mainly to the cooperation of some modifiers that enlarge the flowers. Improvement, however, seems now to have reached maximum, no further marked progress being observable.

With the cooperation of Dr. B. Kanna, I have for several years been experimenting with a character newly named Globose. Gene Globose, which 


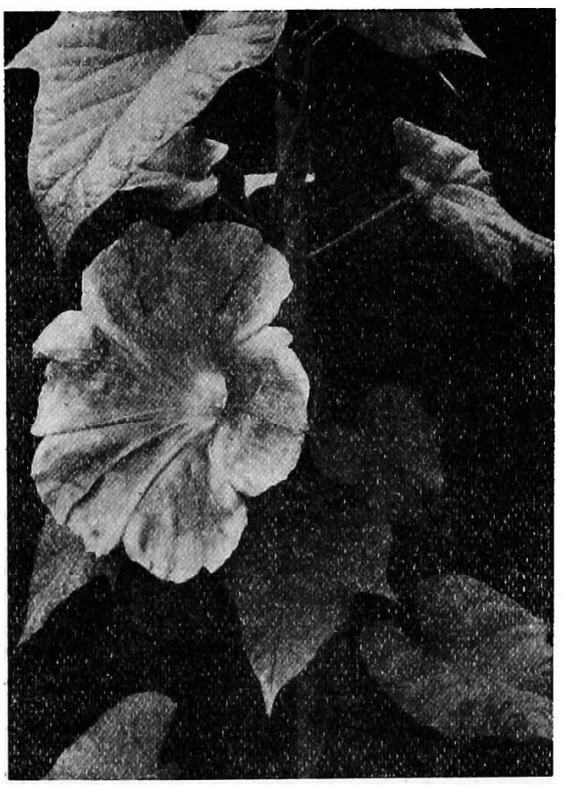

Fig. I. Globose

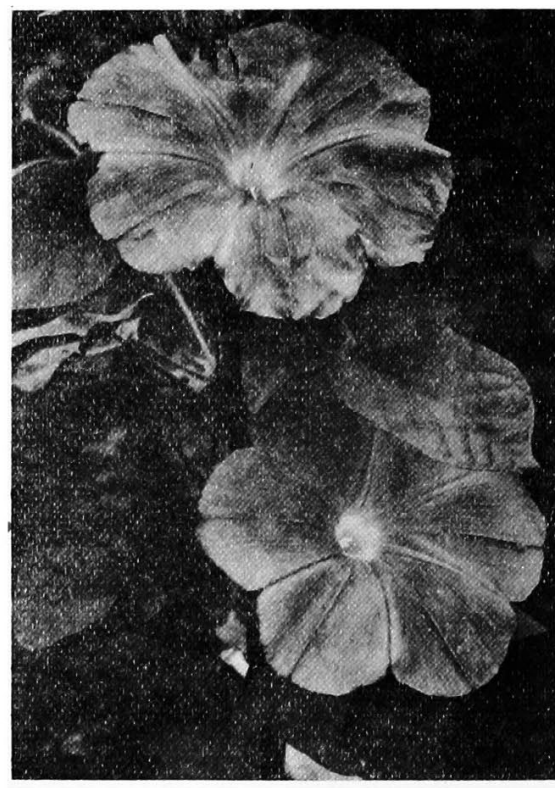

Fig. 3. Retracted Globose dragonfly heterozygous for not-Globose

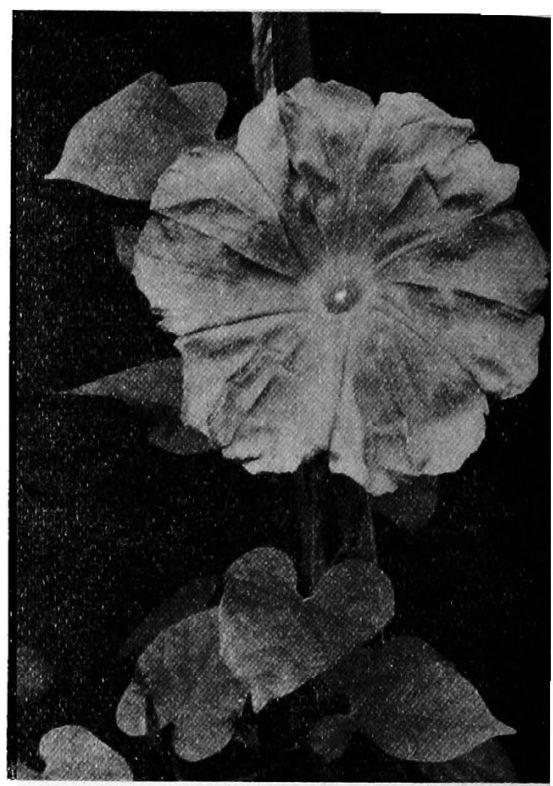

Fig. 2. Retracted Globose

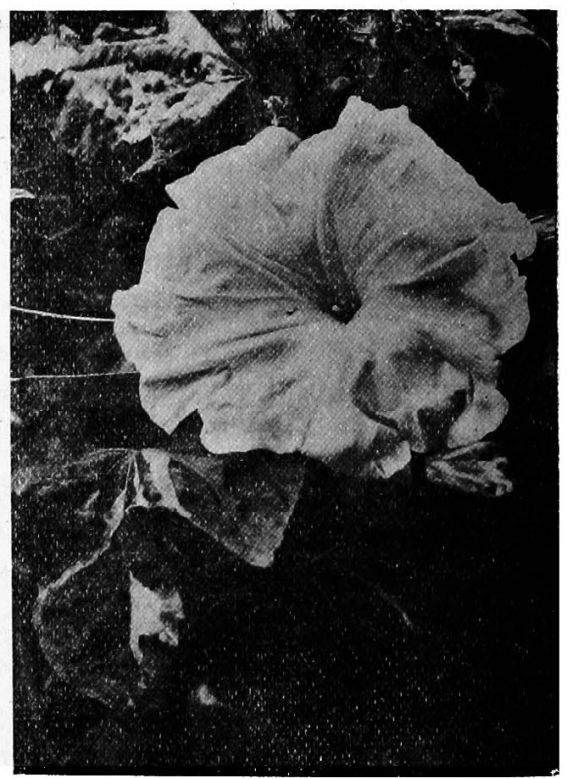

Fig. 4. Retracted Globose raised by Mr. Ozaki 
is a dominant to normal, results in roundish leaves with less-developed lobes and in large flowers, frequently with more than five rays (Fig. I). The leaf form of Globose, which is closely linked with cordate, is modified by two recessive genes, no-lobe and no-lobe-suppressed.1) Expecting large flowers, I sent seeds in I93 I to Mr. N. Hachiuma of Naruo, near Osaka, requesting that he cultivate the Globose plants in pots under the best conditions. The same summer he kindly sent me some pressed flowers that measured 6 Sun, with apologies that he could not raise enough of them for lack of experience in cultivating Globose. To further improve the largest retracted strains, I performed hybridization of them with Globose and obtained some combined, retracted Globose segregates in the hybrid progeny. Under favourable conditions the flowers of retracted Globose bloomed to a very large size in these two seasons (Fig. 2). Owing to the dominance of Globose to normal, the retracted Globose heterozygous for not-Globose blooms also into very large flowers (Fig. 3). I feel confident that retracted Globose will bring about an innovation in the flower size of this plant.

In 1933, Mr. Ozaki selected some plants with roundish leaves from a retracted line and found that they bore very large flowers (Fig. 4). This summer he obtained the same result. He informs me that of his collection of good retracred lines the selected strain bloomed largest. I identified his selected strain to be the retracted Globose described above.

Globose is not a newly found character at all : it has been in cultivation in our gardens, though rarely, as large flowers. Hitherto, the flower size itself, however, was not sufficient to attract the attention of our cultivators. As stated before, the flower size is modified by some genes, so that the retracted Globose may attract special attention when it is combined with certain desirable modifiers, such it did in Mr. Ozaki's case.

In this brief note I wish to call the special attention of zealous cultivators to the importance of the retracted Globose compound in improving the flower size of this plant: From the fact that gene dragonfly generally gives flowers that are somewhat larger when compared with normal, I have repeatedly suggested, from the genetic point of view, that the retracted dragonfly (cicada leaf, or Semiba in Japanese) should be appreciated most of all for the large flowers. Now I should say that the retracted Globose dragonfly is the most hopeful in this respect.

1) Imal, Y. and Kanna, B. Linkage studies in Pharbitts Nil. Genetica, in press. 